\title{
Resistance to hydrogen peroxide in Helicobacter pylori: role of catalase (KatA) and Fur, and functional analysis of a novel gene product designated 'KatA-associated protein', KapA (HP0874)
}

\author{
Andrew G. Harris, ${ }^{1,2}+$ Francis E. Hinds, ${ }^{3}$ Anthony G. Beckhouse, ${ }^{1}$ \\ Tassia Kolesnikow ${ }^{1}$ and Stuart L. Hazell ${ }^{2}$
}

1 School of Microbiology and Immunology, University of New South Wales, Sydney, Australia 2052

2 Centre for Biomedical Research, Faculty of Sciences, University of Southern Queensland, Toowoomba, Australia 4350

3 Centre for Biostructural and Biomolecular Research, University of Western Sydney, Campbelltown, Australia 2560

\author{
Author for correspondence: Stuart L. Hazell. Tel: +61 746312254 . Fax: +6174631 2721. \\ e-mail: s.hazell@usq.edu.au
}

\begin{abstract}
Helicobacter pylori infection elicits an aggressive inflammatory response that the bacterium is able to resist by virtue of its well-adapted antioxidant defence mechanisms. Catalase (KatA) appears to be a key enzyme in this resistance. Upstream of katA, a low-affinity ferric uptake regulator (Fur)-box has been identified. Downstream of katA, an ORF (HP0874) with no known function has also been identified. Non-polar isogenic mutants of katA, fur and HP0874 were constructed by allelic exchange. The impact of these mutations on the catalase activities and bacterial viability following exposure to hydrogen peroxide was studied. Concurrently, the effect of variation in the iron content of the media used to grow the cells was determined. The data showed that catalasedeficient isolates of $\boldsymbol{H}$. pylori were hypersensitive to hydrogen peroxide, whereas wild-type cells could resist $\sim 100 \mathrm{mM}$ hydrogen peroxide. Fur-deficient mutants and cells grown on low-iron-containing medium showed a distinct reduction in catalase activity and increased sensitivity to hydrogen peroxide. The data suggest a direct or indirect effect of Fur and iron on the activity of catalase. HP0874-deficient mutants showed no reduction in catalase activity but showed an increased sensitivity to hydrogen peroxide. That is, the protein encoded by HP0874 appears to have a role in resistance to hydrogen peroxide not directly related to catalase activity. This is the first report of a functional relationship of the product of this ORF. There is evidence of protein-protein interaction between KatA and the product encoded by HP0874, and the name 'KatA-associated protein' (KapA) is proposed.
\end{abstract}

Keywords: influence of iron on catalase activity, oxidative stress response

\section{INTRODUCTION}

Helicobacter pylori is one of the most common agents of infectious disease, infecting between 20 and $90 \%$ of populations in developed and developing countries, respectively (Feldman et al., 1997). H. pylori causes acute (active) or chronic gastritis (Dixon, 1994; Hazell

\footnotetext{
Present address: Medical Microbiology, St Bartholomew's and the Royal London, Queen Mary College, School of Medicine and Dentistry, University of London, London, UK.

Abbreviations: CSA, Campylobacter-selective agar; Fur, ferric uptake regulator; ROS, reactive oxygen species.
}

et al., 1987) and can result in the development of peptic ulcer disease (Graham, 1989) and gastric carcinoma (Parsonnet et al., 1991; Uemura et al., 2001; Wotherspoon et al., 1991).

Gastritis is characterized by an infiltration of plasma cells, lymphocytes, neutrophils and monocytes into the lamina propria and epithelium (Crabtree, 1996; Dixon, 1994; Hazell et al., 1987; Ernst, 1999). Infiltrating inflammatory cells release reactive oxygen species (ROS) (Ernst, 1999). H. pylori is able to withstand ROS, including the oxidative burst due to the frustrated phagocytosis, as a result of the well-adapted antioxidant defences (Hazell et al., 2001; Ramarao et al., 2000). 
Hydrogen peroxide has the potential to cause widespread cellular damage; however, it is the rapid formation of other ROS from hydrogen peroxide, including hydroxyl radicals, which poses more of a threat (Cadenas, 1989; Farr et al., 1988; Nunoshiba et al., 1999). While no enzymic protection against the hydroxyl radicals exists, catalase (EC 1.11.1.6) is responsible for the removal of hydrogen peroxide, whether generated exogenously or endogenously.

H. pylori catalase is expressed in high levels, accounting for approximately $1 \%$ of the cell's total protein (Hazell et al., 1991). The characteristic 'explosive' reaction observed when H. pylori is exposed to hydrogen peroxide is used as an identification test (Harris \& Hazell, 2000). In vitro, $H$. pylori can stimulate the neutrophilic oxidative burst in gastric cell lines (Mooney et al., 1991). Catalase appears to be important to the in vitro survival of $H$. pylori in the presence of professional phagocytes (Ramarao et al., 2000), although not essential in vitro under standard growth conditions (indicating that endogenously generated hydrogen peroxide is not a problem) (Manos et al., 1997; Odenbreit et al., 1996; Westblom et al., 1992).

Iron, in the presence of hydrogen peroxide, acts as a catalyst to generate more ROS. The ferric uptake regulator (Fur) and Fur homologues, such as PerR, are involved in the regulation of enzymes involved in the detoxification of ROS (Herbig \& Helmann, 2001), for example sodA of Escherichia coli (Naik \& Hassan, 1992). Fur is an iron-dependent positive regulator of katA in Staphylococcus aureus (Horsburgh et al., 2001) and a negative regulator of catalase-peroxidase (catC) of Streptomyces coelicolor (Hahn et al., 2000). PerR of Bacillus subtilis is involved in sensing hydrogen peroxide (Herbig \& Helmann, 2001), and several organisms possess PerR, including Campylobacter jejuni (Van Vliet et al., 1999); however, H. pylori appears to lack PerR (Alm et al., 1999; Tomb et al., 1997).

The catalase of $H$. pylori (KatA) has been characterized (Hazell et al., 1991) and subsequently sequenced (Manos et al., 1997; Odenbreit et al., 1996). A putative Fur-box upstream of the coding region suggested a possible role for Fur in the regulation of KatA (Manos et al., 1997; Odenbreit et al., 1996). Delany et al. (2001b) demonstrated that the putative Fur-box upstream of $k a t A$ was modulating the expression of $\operatorname{fr} p B$. However, a low-affinity Fur-binding region was identified closer to, but not overlapping, the -35 and -10 sites of kat $A$. Delany et al. (2001b) were unable to detect any transcriptional difference in the expression of katA between the wild-type and a fur-deficient mutant of $H$. pylori. Despite these data, the potential for iron and Fur to influence catalase expression or activity in $H$. pylori is worthy of further investigation.

Approximately 150 bp downstream of kat A, an ORF of unknown function has been identified (Alm et al., 1999; Manos et al., 1997; Odenbreit et al., 1996; Tomb et al., 1997). This ORF, designated HP0874 by TIGR (Tomb et al., 1997), appears to be conserved in all strains of H. pylori (Salama et al., 2000) with the only apparent homologue being a putative gene encoding a protein of unknown function in Pasteurella multocida (http://www.tigr.org) (May et al., 2001).

Putative stem-loop structures in the intergenic regions between HP0874 and katA suggest that both kat A and HP0874 are transcribed independently. However, there are no recognizable RNA polymerase binding sites upstream of HP0874 (Manos, 1998; Odenbreit et al., 1996). Using a yeast two-hybrid model, Rain et al. (2001) have indicated that the protein encoded by HP0874 interacts with KatA. This possible interaction suggests a role for HP0874, directly or indirectly, in the oxidative stress response of $H$. pylori. When HP0874 was disrupted using transposon mutagenesis (Odenbreit et al., 1996), no differences in the catalase activities of cell-free extracts were observed, resulting in the conclusion that HP0874 does not affect catalase activity.

The in vitro response of $H$. pylori to hydrogen peroxide has been the subject of limited investigation, despite the purification and molecular characterization of KatA (Alm et al., 1999; Hazell et al., 1991; Manos et al., 1997; Odenbreit et al., 1996; Tomb et al., 1997). Further, studies of the role of Fur and Fur-like homologues and the importance of iron in the regulation of the oxidative stress response of $H$. pylori have been limited. The aims of the current investigation were to study the roles of KatA, HP0874 and Fur and extracellular iron in the response of $H$. pylori to hydrogen-peroxide-induced stress. We present data indicating a role for HP0874 in resistance to oxidative damage and propose the name 'KatA-associated protein' (kapA).

\section{METHODS}

Bacteria and routine culture conditions. Helicobacter pylori strain 26695 was obtained from the culture collection at the School of Microbiology and Immunology, University of New South Wales. Cultures of $H$. pylori were maintained on Campylobacter-selective agar (CSA) and incubated for 36$48 \mathrm{~h}$ in a $\mathrm{CO}_{2}$ incubator (Heraeus Instruments) at $37^{\circ} \mathrm{C}$ with a reduced oxygen environment (micro-aerobic) consisting of $10 \% \mathrm{CO}_{2}$ in air and $95 \%$ relative humidity. Culture purity was confirmed by phase-contrast microscopy, and rapid positive urease and catalase activities as determined by the addition of cells to urease reagent (Hazell et al., 1987) and hydrogen peroxide, respectively.

Cultures of Escherichia coli DH5 $\alpha$ were grown on LuriaBertani agar or broth as described by Sambrook et al. (1989). The agar was supplemented with antibiotics as appropriate (50 $\mu \mathrm{g}$ ampicillin $\mathrm{ml}^{-1}$ or $50 \mu \mathrm{g}$ kanamycin $\mathrm{ml}^{-1}$ ).

A summary of bacteria used in the current study and their genotypes are shown in Table 1.

Media preparation. Cultures of $H$. pylori were maintained on CSA consisting of blood agar base No. II (Oxoid) $5 \%(\mathrm{v} / \mathrm{v})$ defibrinated horse blood (Oxoid), $4.2 \mathrm{mg}$ amphotericin $\mathrm{B} \mathrm{ml} \mathrm{m}^{-1}$ (ER Squibb and Sons) and Skirrow's selective supplement (Skirrow, 1977). CSA using Columbia agar base (Oxoid) in preference to blood agar base no. II was used for the transformation of $H$. pylori, with kanamycin $\left(20 \mu \mathrm{g} \mathrm{ml}^{-1}\right)$ supplementing the media as appropriate. 
Preparation of iron-depleted media. IsoSensitest agar and broth (Oxoid) are chemically defined media used in antibiotic sensitivity testing and support growth of $H$. pylori if supplemented with serum (Hazell et al., 1989). These media were prepared as per the manufacturer's instructions. In these experiments, we used Chelex to remove iron and other ions, and reconstituted the medium with the ions, apart from iron, according to the published formulation of IsoSensitest medium. We chose Chelex over other iron chelators as it facilitated the physical removal of iron from the medium, eliminating the potential for $H$. pylori to extract the iron from the chelated complexes in situ, a potential problem when other chelators such as Desferal or EGTA are used.

Horse serum (100 ml) (Oxoid) was mixed with $25 \mathrm{~g}$ Chelex (Sigma) with continual stirring at $4{ }^{\circ} \mathrm{C}$ for $16 \mathrm{~h}$ to remove divalent cations. The Chelex was regenerated and the process of removing divalent cations repeated. After removal of divalent cations, the horse serum was filter-sterilized through a $0.22 \mu \mathrm{m}$ filter and stored frozen until required. The IsoSensitest broth (1 l) was depleted of divalent cations using Chelex as outlined above. Agar $\left(15 \mathrm{~g} \mathrm{l}^{-1}\right)$ was added to the broth, sterilized by autoclaving and allowed to cool to $48{ }^{\circ} \mathrm{C}$ before the addition of $100 \mathrm{ml}$ of divalent-cation-depleted horse serum, Skirrow's selective supplement and amphotericin B. The medium was supplemented with $1 \mathrm{mg} \mathrm{CuSO}_{4}$, $\mathrm{CoSO}_{4} \cdot 7 \mathrm{H}_{2} \mathrm{O}, \mathrm{ZnSO}_{4} \cdot 7 \mathrm{H}_{2} \mathrm{O}$ and $\mathrm{MgSO}_{4} .7 \mathrm{H}_{2} \mathrm{O} \mathrm{l}^{-1}, 2 \mathrm{mg}$ $\mathrm{MnCl}_{2} \mathrm{l}^{-1}$ and $100 \mathrm{mg}$ calcium gluconate $\mathrm{l}^{-1}$ replacing cations removed by Chelex, in accordance with the chemical definition of IsoSensitest. The medium was used within $24 \mathrm{~h}$ of preparation.

Preparation of iron-supplemented media. Iron-supplemented medium was made by the addition of $\mathrm{FeSO}_{4}(100 \mathrm{mM})$ to IsoSensitest agar. The medium was supplemented with sterile horse serum $(5 \% \mathrm{v} / \mathrm{v})$, Skirrow's selective supplement and amphotericin $\mathrm{B}$, and used within $24 \mathrm{~h}$ of preparation.

Atomic absorbance spectroscopy. To quantify the amount of iron present in each of the media used to culture H. pylori, atomic absorbance spectroscopy was carried out on $20 \mathrm{ml}$ samples of broth prior to the addition of agar. This procedure was performed using a series of $\mathrm{FeSO}_{4}$ standards ranging from $0 \cdot 1$ p.p.m. Fe to 100 p.p.m. Fe as a reference. The spectra were obtained using a Varian SpectrAA-200 (Varian) and a hollow cathode lamp for Fe (Photron) as per the manufacturer's instructions. All spectra were determined twice. The presence of erythrocytes in the blood-based media prohibited the determination of iron content.

Protein concentration determination. The protein concentration of each sample was determined using the bicinchonic acid method based on a microtitre plate assay (Pierce). The concentration of each sample was calculated based on the values obtained for bovine serum albumin standards, these being $0 \cdot 2,0 \cdot 4,0 \cdot 6,0 \cdot 8,1 \cdot 0$ and $1 \cdot 2 \mathrm{mg}$ protein $\mathrm{ml}^{-1}$.

Catalase activities of cell-free extracts. Cell-free extracts of $H$. pylori were obtained using the freeze-thaw method of lysis (Mendz et al., 1998). The catalase activities of the cell-free extracts of H. pylori 26695 wild-type and 26695 fur::aphA3 grown on different media were determined using the method of Beers \& Sizer (1952). The data, expressed as $\mu$ mol hydrogen peroxide decomposed $\min ^{-1}(\mathrm{mg} \text { protein })^{-1}$, were determined a total of nine times for each sample. The limit of sensitivity for the test was 1 unit (mg protein $)^{-1}$.

Measuring of hydrogen peroxide concentration. The hydrogen peroxide was diluted so the absorbance measured at $240 \mathrm{~nm}$ in a quartz cuvette, with a path length of $1 \mathrm{~cm}$, was between $0 \cdot 1$ and $0 \cdot 9$. The concentration of hydrogen peroxide was calculated using the absorption coefficient of 43.481 $\mathrm{mol}^{-1} \mathrm{~cm}^{-1}$ (Beers \& Sizer, 1952; Hazell et al., 1991).

Time-dependent killing by hydrogen peroxide. Fresh $24 \mathrm{~h}$ cultures of $H$. pylori 26695 wild-type, katA, HP0874 (kapA) and fur isogenic mutants, grown on CSA (blood-based media), IsoSensitest agar (serum-based), iron-depleted or ironsupplemented IsoSensitest Agar were harvested in $0.9 \%(\mathrm{w} / \mathrm{v})$ $\mathrm{NaCl}$ (physiological saline). The cells were washed once and resuspended in physiological saline. The optical densities of the cell suspensions, measured at $600 \mathrm{~nm}$, were adjusted to $0 \cdot 7$. Cells were used immediately.

At time zero, $200 \mu \mathrm{l}$ of the cell suspension was added to $1.8 \mathrm{ml}$ of either 98 or $49 \mathrm{mM}$ hydrogen peroxide. Immediately after the addition of the cell suspension, $100 \mu \mathrm{l}$ was removed and combined with $100 \mu \mathrm{l} 1 \%$ (w/v) bovine liver catalase (Sigma) to dismutate the hydrogen peroxide. Four 10 -fold dilutions were made in physiological saline, which were cultured in $10 \mu \mathrm{l}$ spots, in triplicate, onto 'dry' CSA plates. Every $4 \mathrm{~min}$, the process was repeated, for a total of $60 \mathrm{~min}$. The agar plates were incubated for 3-5 days, after which individual colonies were counted. Negative controls, where water was used in place of hydrogen peroxide, were carried out with all strains grown on all four different media. The response to hydrogen peroxide by the isogenic mutants was determined at least twice for each medium.

Molecular manipulation of $\boldsymbol{H}$. pylori. Genomic DNA from $H$. pylori 26695 was extracted using the Wizard DNA preparation kit (Promega). Plasmids were extracted from E. coli using an alkaline lysis-based kit (Quantum mini prep, Bio-Rad). All restriction digests and other molecular manipulations were carried out according to the manufacturer's instructions. RNA was extracted from $H$. pylori using the RNeasy RNA extraction kit (Qiagen), and the quality of RNA was assessed by formaldehyde gel electrophoresis as described by Sambrook et al. (1989). Sequencing was carried out using the BigDye Terminator kit from ABI PRISM (Applied Biosystems). The separation of labelled fragments of DNA was carried out using a 377 sequencer (Applied Biosystems) automated sequencing facility, University of New South Wales. Results were obtained using the INHERIT software package (Applied Biosystems). RT-PCR was carried out using the Enhanced Avian RT-PCR kit (Sigma-Aldrich).

RT-PCR. RT-PCR was carried out according to the manufacturer's instructions. The primer sequences designed for RT-PCR are listed in Table 1. Primer pairs (KatA 557F, KatA 1242R; KatA 1001F, KapA 103R; KapA 423F, KapA 824R; Fig. 1) were designed to allow the detection of transcripts specific for $k a t A$, specific for $k a p A$ and for the intragenic region between the two genes. The primers were annealed stepwise $\left(70{ }^{\circ} \mathrm{C}\right.$ for $2 \mathrm{~min} ; 65,60,55,50$ and $45^{\circ} \mathrm{C}$ for $1 \mathrm{~min}$ each step) before the reverse transcriptase was added. The high temperatures at the beginning of the stepwise annealing denatures the stem-loop structures in the RNA (Tillet et al., 2000). The RT reaction was performed at $45^{\circ} \mathrm{C}$ for $30 \mathrm{~min}$, followed by five cycles of $50^{\circ} \mathrm{C}$ for $1 \mathrm{~min}, 53{ }^{\circ} \mathrm{C}$ for $1 \mathrm{~min}$ and $56^{\circ} \mathrm{C}$ for $1 \mathrm{~min}$. A control without the reverse transcriptase was used to determine whether the RNA was free of DNA. PCR followed using the following parameters: $94^{\circ} \mathrm{C}$ for 4 min and a cycle of $94^{\circ} \mathrm{C}$ for $10 \mathrm{~s}, 50^{\circ} \mathrm{C}$ for $10 \mathrm{~s}$ and $72{ }^{\circ} \mathrm{C}$ for $1 \mathrm{~min}$, repeated 35 times. A final elongation step of $72^{\circ} \mathrm{C}$ for $7 \mathrm{~min}$ followed. RT-PCR products were analysed using agarose gel electrophoresis.

Polymerase chain reaction. Fragments of DNA to be cloned into vectors were amplified using PCR. All PCRs were carried 
Table 1. Bacterial strains, plasmids and primer sequences used in the current study

\begin{tabular}{|c|c|c|}
\hline $\begin{array}{l}\text { Strain, plasmid } \\
\text { or primer }\end{array}$ & Characteristics or sequence & Source \\
\hline \multicolumn{3}{|l|}{ Helicobacter pylori } \\
\hline 26695 wild-type & Wild-type, genome sequenced & $\begin{array}{l}\text { Eaton et al. (1991); } \\
\text { Tomb et al. (1997) }\end{array}$ \\
\hline 26695 katA::aphA3 & $\begin{array}{l}\text { Allelic exchange product of } 26695 \text { when transformed with p } \Delta \text { KatA; catalase- } \\
\text { deficient }\end{array}$ & This study \\
\hline 26695 kapA::aphA3 & Allelic exchange product of 26695 when transformed with $\mathrm{p} \Delta \mathrm{KapA}$ & This study \\
\hline 26695 fur::aphA3 & Allelic exchange product of 26695 when transformed with $\mathrm{p} \Delta \mathrm{Fur}$ & This study \\
\hline \multicolumn{3}{|l|}{ Escherichia coli } \\
\hline DH $5 \alpha$ & $\begin{array}{l}\mathrm{F}^{-} \text {supE44 } \Delta(\text { lacZYA-argF }) \text { U169 }(\phi 80 \text { lacZ } \Delta M 15) \text { hsdR17 }\left(\mathrm{r}_{\mathrm{k}}^{-} \mathrm{m}_{\mathrm{k}}^{+}\right) \text {recA1 endA1 } \\
\text { gyrA96 thi-1 relA1 }\end{array}$ & Life Technologies \\
\hline \multicolumn{3}{|l|}{ Plasmids } \\
\hline pGem-T easy & $\mathrm{Ap}^{\mathrm{r}}$, cloning vector & Promega \\
\hline pUC19 & Ap ${ }^{r}$, cloning vector & New England Biolabs \\
\hline pKSF & $\mathrm{Ap}^{\mathrm{r}} \mathrm{Km}^{\mathrm{r}}$, source of $a p h A 3$ & Copass et al. (1997) \\
\hline pKatA & $\mathrm{Ap}^{\mathrm{r}}, 1863 \mathrm{bp}$ PCR fragment containing H. pylori katA cloned into pGem-T easy & This study \\
\hline $\mathrm{p} \Delta \mathrm{KatA}$ & $\begin{array}{l}\text { Ap }^{r} \mathrm{Km}^{\mathrm{r}} \text {, katA ::aphA3.1.2 kb aphA3 from pKSF ligated into unique ClaI site of } \\
\text { katA }\end{array}$ & This study \\
\hline pKapA & $\begin{array}{l}\text { Ap }^{\mathrm{r}}, 1918 \text { bp PCR fragment containing H. pylori kapA (HP0874) directionally } \\
\text { cloned into SacI and SalI sites of pUC19 }\end{array}$ & This study \\
\hline pKapA II & $\begin{array}{l}\mathrm{Ap}^{\mathrm{r}} \text {, construct with PstI site removed from vector backbone by double digest } \\
\text { using SapI and SalI, resulting in unique PstI site in kapA }\end{array}$ & This study \\
\hline pKapA III & $\mathrm{Ap}^{\mathrm{r}}$, unique PstI site in kapA (HP0874) destroyed, unique $\mathrm{XboI}$ site created & This study \\
\hline $\mathrm{p} \Delta \mathrm{KapA}$ & $\begin{array}{l}\mathrm{Ap}^{\mathrm{r}} \mathrm{Km}^{\mathrm{r}}, k a p A:: a p h A 3,1 \cdot 2 \mathrm{~kb} a p h A 3 \text { from pKSF ligated into unique XhoI site } \\
\text { of } k a p A(\mathrm{HP} 0874) \text { [in pKapA (HP0874) III] }\end{array}$ & This study \\
\hline pFur & $\begin{array}{l}\mathrm{Ap}^{\mathrm{r}}, 1.65 \mathrm{~kb} \text { PCR fragment containing } H . \text { pylori fur directionally cloned into PstI } \\
\text { and BamHI sites of pUC19 }\end{array}$ & This study \\
\hline $\mathrm{p} \Delta \mathrm{Fur}$ & $\mathrm{Ap}^{\mathrm{r}} \mathrm{Km}^{\mathrm{r}}$, fur::aphA3;1.2 $\mathrm{kb} a p h A 3$ from pKSF ligated to unique $B c l \mathrm{l}$ site in fur & This study \\
\hline \multicolumn{3}{|l|}{ Primers } \\
\hline HpKatA F & GacgtcgacCGGCTTGGTGTCAGATTACG; recognition site for SalI underlined & This study \\
\hline HpKatA R & $\begin{array}{l}\text { GacgtcgacTGCAGAATCAAAATCAATGCTG; recognition site for SalI } \\
\text { underlined }\end{array}$ & This study \\
\hline HpKapA F & $\begin{array}{l}\text { GtggagctcCGATTCCATCCGTTTGATGTTAC; recognition site for SacI } \\
\text { underlined }\end{array}$ & This study \\
\hline HpKapA R & $\begin{array}{l}\text { GaggtcgacCTCCATAAAAGGTAGCATCACCAAC; recognition site for SalI } \\
\text { underlined }\end{array}$ & This study \\
\hline XhoI Linker I & AGATCTCGAGTGCA; recognition site for XhoI underlined & This study \\
\hline XhoI Linker II & CTCGAGATCTTGCA; recognition site for XhoI underlined & This study \\
\hline HpFur F & $\begin{array}{l}\text { TagcctgcagTGATACGCATTATAACCTTACTAGC; recognition site for PstI } \\
\text { underlined }\end{array}$ & This study \\
\hline HpFur R & $\begin{array}{l}\text { AgatggatccTCAAATTAAAATTATGAGATTGGTG; recognition site for BamHI } \\
\text { underlined }\end{array}$ & This study \\
\hline Kan I F & $\begin{array}{l}\text { CcatcgatctcgagCAGCGCGCTTATCAATATATC; recognition sites for ClaI in } \\
\text { bold and XhoI underlined }\end{array}$ & Copass et al. (1997) \\
\hline Kan II F & $\begin{array}{l}\text { TaagatctgatcaCAGCGCGCTTATCAATATATC; recognition sites for BclI } \\
\text { underlined }\end{array}$ & Copass et al. (1997) \\
\hline Kan I R & $\begin{array}{l}\text { CcatcgatctcgagTTTTAGACATCTAAATCTAGCTAC; recognition sites for } \\
\text { ClaI in bold and XhoI underlined }\end{array}$ & Copass et al. (1997) \\
\hline Kan II R & $\begin{array}{l}\text { TcgcgcgctgatcaTTTTTAGACATCTAAATCTAGGTAC; recognition sites for } \\
\text { BclI underlined }\end{array}$ & Copass et al. (1997) \\
\hline KatA $557 \mathrm{~F}$ & $\begin{array}{l}\text { TCCCTAAATCTTTCCGCC; forward primer used to sequence katA from } H \text {. } \\
\text { pylori } 26695 \text { katA::aphA3; also used in RT-PCR }\end{array}$ & This study \\
\hline KatA $1001 \mathrm{~F}$ & $\begin{array}{l}\text { GAAAGAGTTTGAAGTGTGG; reverse primer used to sequence katA from } H \text {. } \\
\text { pylori } 26695 \text { katA::aphA3; also used in RT-PCR }\end{array}$ & This study \\
\hline
\end{tabular}


Table 1. (cont.)

\begin{tabular}{|c|c|c|}
\hline $\begin{array}{l}\text { Strain, plasmid } \\
\text { or primer }\end{array}$ & Characteristics or sequence & Source \\
\hline KatA $1249 \mathrm{R}$ & $\begin{array}{l}\text { CCACACTTCAAACTCTTTC; forward primer used to sequence kapA } \\
\text { (HP0874) from H. pylori } 26695 \text { kapA::aphA3; also used in RT-PCR }\end{array}$ & This study \\
\hline KapA 103 R & $\begin{array}{l}\text { TTGCAGCACTCCCTTTGC; reverse primer used in RT-PCR of kapA } \\
\text { (HP0874) and KatA intragenic region from H. pylori } 26695\end{array}$ & This study \\
\hline KapA $423 \mathrm{~F}$ & $\begin{array}{l}\text { AACATTGCCAACCAGCTC; forward primer used in RT-PCR of kapA } \\
\text { (HP0874) from H. pylori } 26695\end{array}$ & This study \\
\hline KapA 824 R & $\begin{array}{l}\text { CCTAAATCCCTACCATCC; reverse primer used to sequence kapA (HP0874) } \\
\text { from } H \text {. pylori } 26695 \text { kapA::aphA3; also used in RT-PCR }\end{array}$ & This study \\
\hline Fur $120 \mathrm{~F}$ & $\begin{array}{l}\text { GTCATGGCTAATCAGCTTGG; forward primer used to sequence fur from } \\
\text { H. pylori } 26695 \text { fur::aphA3 }\end{array}$ & This study \\
\hline Fur $405 \mathrm{R}$ & $\begin{array}{l}\text { CACACACCTAAGCCCTGAAG; reverse primer used to sequence fur from } \\
\text { H. pylori } 26695 \text { fur::aphA3 }\end{array}$ & This study \\
\hline $\mathrm{M} 13 / \mathrm{pUC} F$ & CGCCAGGGTTTTCCCAGTCACGAC & New England Biolabs \\
\hline M13/pUC R & AGCGGATAACAATTTCACACAGGA & New England Biolabs \\
\hline
\end{tabular}

*Primer sequences: upper-case letters indicate nucleotides present in template DNA, and lower-case letters indicate nucleotides added for cloning purposes.

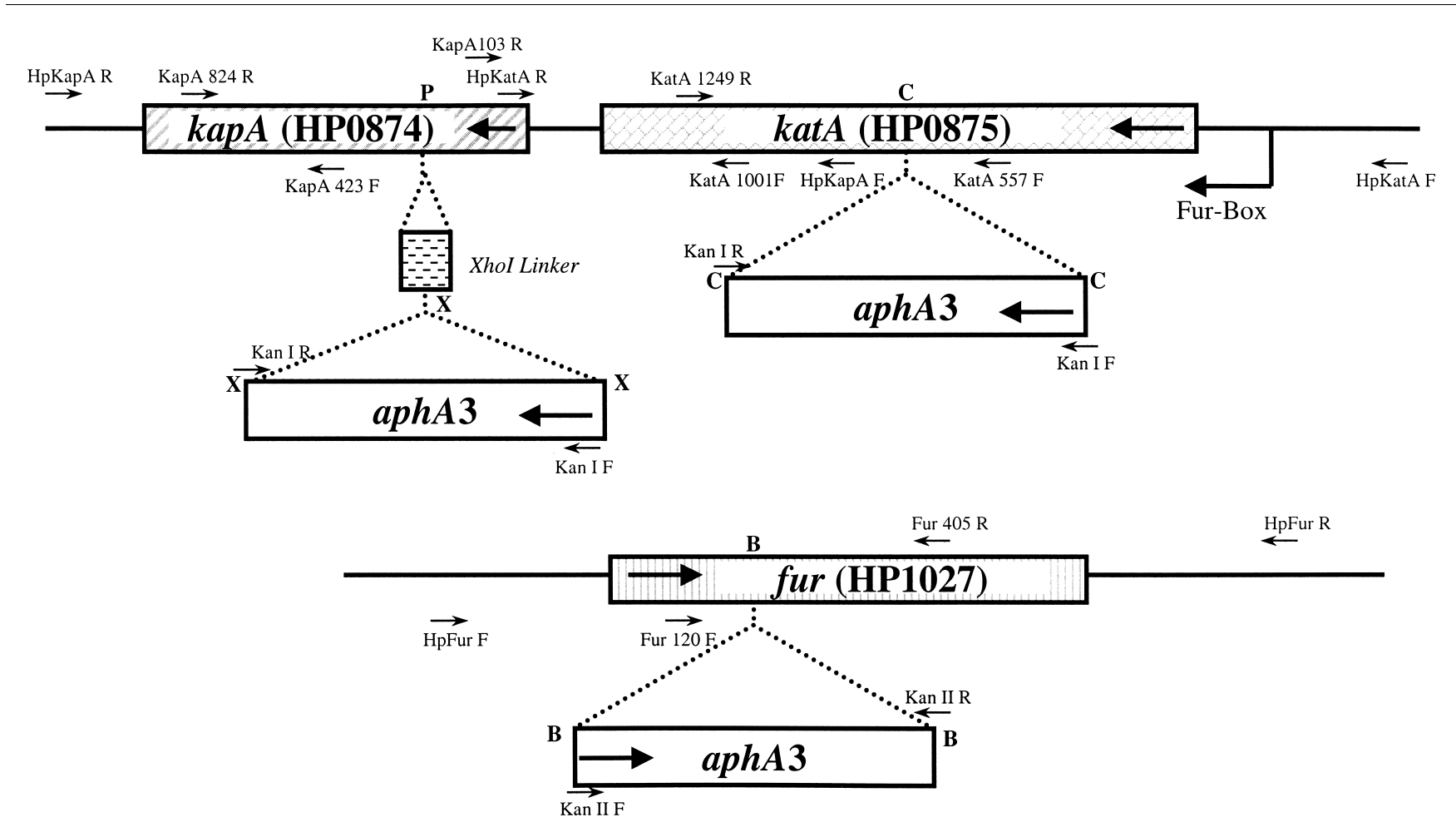

Fig. 1. Schematic diagram of the insertional deactivation of katA (HP0875), kapA (HP0874) and fur (HP1027). Thick arrows indicate the direction of transcription, and smaller arrows indicate the position and direction of the PCR primers used in the cloning and sequencing of these genes. Restriction enzyme abbreviations: B, Bcll; C, Clal; P, Pstl; X, Xhol. See Table 1 for sequences of primers and Xhol linkers.

out in $20 \mu \mathrm{l}$ volumes and consisted of the appropriate volume of PCR buffer, $2 \cdot 125 \mathrm{mM} \mathrm{MgCl}_{2}$, dNTPs (final concentration $0 \cdot 2 \mathrm{mM}$ each dNTP), 10-100 ng template DNA, 10 pmol each primer and $0.5 \mathrm{U}$ of a $(9: 1) \mathrm{Taq} / \mathrm{Pfu} \mathrm{DNA}$ polymerase mix. All primers used in the current study are listed in Table 1 and were synthesized at Genset Pacific Oligos (Lismore, Australia) and obtained using previously published sequences for kat A, HP0874 (kapA), fur (Tomb et al., 1997) and aphA3 (Copass et al., 1997). The reactions were carried out in an Applied Biosystems thermal cycler using identical cycling parameters. These parameters were as follows: $80^{\circ} \mathrm{C}$, until the DNA polymerase had been added, $94^{\circ} \mathrm{C}$ for $4 \mathrm{~min}$, followed by 30 
cycles of $94{ }^{\circ} \mathrm{C}$ for $10 \mathrm{~s}, 50{ }^{\circ} \mathrm{C}$ for $10 \mathrm{~s}$ with elongation at $68^{\circ} \mathrm{C}$ for $1 \mathrm{~min}$ per $\mathrm{kb}$ to be extended. A final extension period of $8 \mathrm{~min}$ at $68^{\circ} \mathrm{C}$ was performed before PCR fragments were analysed by agarose gel electrophoresis.

Construction of pKatA and psKatA. Genomic DNA from $H$. pylori 26695 was extracted and katA amplified using the PCR primers HpKatA F and HpKatA R. The 1863 bp PCR fragment was cloned into the multiple cloning site of pGEM-T Easy (Promega) and transformed into chemically competent E. coli DH5 $\alpha$, as described by Hanahan (1983). The construct, pKatA, was $4896 \mathrm{bp}$ in length, and a unique site recognized by the restriction endonuclease ClaI was found 819 bp downstream of the ATG start codon of katA. PCR was used to amplify the gene encoding kanamycin resistance, kanamycin phosphotransferase, aphA3 $\left(\mathrm{Km}^{\mathrm{r}}\right)$ with primers Kan I F and Kan I R, designed to be in-frame, in the same orientation and lacking transcriptional terminator sequences, using pKSF as the template (Copass et al., 1997). The PCR product was digested by ClaI (New England Biolabs) and ligated into the unique ClaI site of pKatA, using $\mathrm{T}_{4}$ DNA ligase (New England Biolabs). Restriction mapping, PCR and nucleotide sequencing were used to confirm the new construct, $\mathrm{p} \Delta \mathrm{Kat} \mathrm{A}$, and to determine the orientation of $a p h A 3$ relative to kat $A$ (Fig. 1).

Construction of pKapA, pKapA II, pKapA III and p $\Delta$ KapA. HP0874 (kapA) was amplified using primers HpKapA F and HpKapA R (1918 bp) and genomic DNA extracted from $H$. pylori 26695 as a template. The PCR product was directionally cloned into the $\mathrm{SacI}$ and SalI restriction sites in the multiple cloning site of pUC19. The resulting plasmid, pKapA, was digested with SapI and SalI to remove the PstI site in the vector backbone. The non-compatible sticky ends produced from the double digest were filled in using a Klenow fragment, as described by Sambrook et al. (1989). The linear plasmid was gel-purified and allowed to self-ligate to form a new construct termed pKapA II. The removal of the PstI site from the vector resulted in a single $P$ st $I$ site, 147 bp downstream from the ATG start codon of HP0874 (kapA). A new restriction site was created by digestion of $\mathrm{pKapA}$ II with PstI and ligation with an equimolar linker mix (XhoI linker 1 and XhoI linker 2). Upon ligation to the linker, the PstI site in the pKapA II was destroyed, and a unique $X h_{o} I$ restriction site was created. To ensure successful construction of the unique XhoI site, Pst I was incorporated into the ligation reaction, further ensuring that only plasmids with the XhoI restriction site were transformed into E. coli. The construct was termed pKapA III. PCR was used to amplify aphA3 using the primers Kan I F and Kan I R with pKSF as the template (Copass et al., 1997). The PCR product was digested by $X h o I$ and inserted into the unique $X h o I$ restriction site in pKapA III. The resulting construct, $\mathrm{p} \Delta \mathrm{KapA}$, and orientation of aphA3 relative to HP0874 (kapA) were confirmed by restriction mapping, PCR and nucleotide sequencing.

Construction of pFur and p $\Delta$ Fur. A $1.65 \mathrm{~kb}$ fragment containing fur was amplified from $H$. pylori 26695 genomic DNA using the primers HpFur F and HpFur R. Recognition sites for Pst I and BamHI were incorporated into the $5^{\prime}$ end of these primers to allow directional insertion into the pUC19 vector. The construct containing fur was termed pFur. A unique site recognized by the restriction endonuclease $B c l$ I was present $291 \mathrm{bp}$ downstream of the ATG start codon of fur. The kanamycin resistance cassette, $a p h A 3$, was amplified by PCR using the primers Kan II F and Kan II R. The PCR product was digested with $B c l$ I and ligated in-frame and lacking transcriptional terminator sequences into the unique $B c l$ I restriction site within the ORF of the fur gene. The ligation product, termed $\mathrm{p} \Delta$ Fur, was transformed into chemically competent $E$. coli. PCR and nucleotide sequencing were used to confirm that aphA3 was in the same orientation as fur.

Transformation of $\boldsymbol{H}$. pylori. H. pylori was grown on CSA made using Columbia agar base (Oxoid) for $24 \mathrm{~h}$ at $37^{\circ} \mathrm{C}$ in a micro-aerobic environment. Cells were harvested with Brain Heart Infusion (Oxoid), centrifuged at room temperature for $30 \mathrm{~s}$ at $15000 \mathrm{~g}$ and resuspended in a minimal volume of $0.9 \%$ $(\mathrm{w} / \mathrm{v}) \mathrm{NaCl}$. The resultant cell suspension was placed onto dry CSA plates in well-separated $10 \mu \mathrm{l}$ aliquots and allowed to incubate at room temperature for $15 \mathrm{~min}$, before being incubated in a $\mathrm{CO}_{2}$ incubator for $5 \mathrm{~h}$. Ten microlitres of plasmid DNA (varied concentrations), prepared using the Quantum midi prep (Bio-Rad) was mixed with the bacterial 'spots' growing on CSA. The cells were incubated for a further $24 \mathrm{~h}$ before transferring the bacteria to CSA (Columbia agar base) containing $20 \mu \mathrm{g}$ kanamycin $\mathrm{ml}^{-1}$. The cells were incubated for 24-72 h until colonies were present. DNA from the isolates was subjected to PCR and nucleotide sequencing to confirm that homologous recombination had occurred.

Statistical analysis. Statistical comparisons of the catalase activities of the Fur isogenic mutants and wild-type cells grown on the same media were carried out using the Mann-Whitney $U$-test. A statistical analysis between the same strains grown on different media was carried out using the Kruskal-Wallis analysis (SPSS).

\section{RESULTS}

\section{RT-PCR of katA and kapA (HP0874)}

RT-PCR was used to determine whether katA and kapA were part of a multi-cistronic operon. Products were observed when primers were directed towards the $3^{\prime}$ end of katA (KatA 557F; KatA 1249R) and kapA (KapA $423 \mathrm{~F}$; KapA 824R). No product was detected, however, with primers KatA $1001 \mathrm{~F}$ and KapA 103R, designed to detect a transcript that spanned the intragenic region, if it existed (Fig. 2a). This would indicate that katA and HP0874 are not part of a multi-cistronic operon, as there does not appear to be a single transcript for the two genes. The primer pairs produced products of the desired size when genomic DNA of $H$. pylori was used as a template in a PCR (not shown).

\section{Construction of isogenic mutants of katA, kapA (HP0874) and fur}

Isogenic mutants of katA, HP0874 (kapA) and fur were all created by allelic exchange. To validate the construction of the isogenic mutants, genomic DNA was extracted from the kanamycin-resistant isolates and subjected to PCR using the oligonucleotide primers used to clone the genes into the cloning vectors (Table 1). As determined by the size of the PCR products, each of the genes, katA, HP0874 (kapA) and fur, was successfully disrupted by aphA3 (Fig. 3). Furthermore, the presence of $a p h A 3$ in the isogenic mutants was confirmed by PCR using the primers Kan I F and Kan I R (Fig. 3). The PCR products of $H$. pylori 26695 katA::aphA3, H. pylori 26695 kapA::aphA3 and H. pylori 26695 fur::aphA3 were sequenced using the oligonucleotide primers out- 
(a)

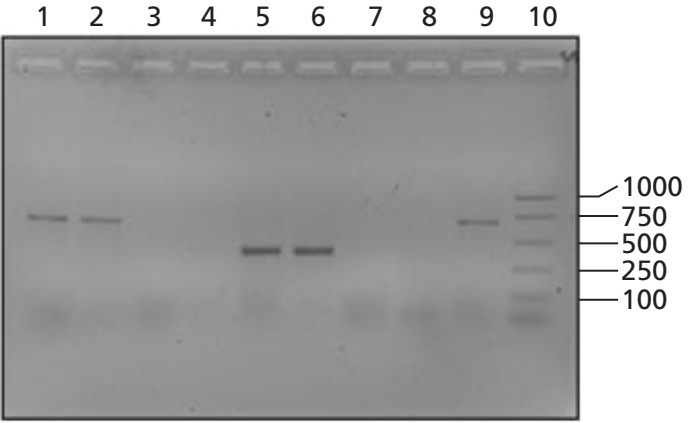

(b)

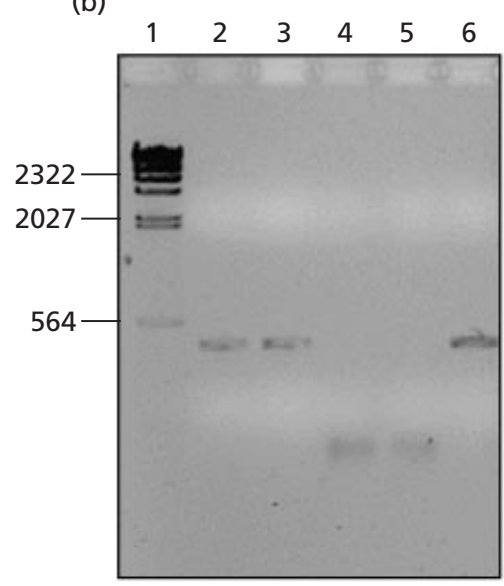

Fig. 2. (a) Agarose gel of RT-PCR of RNA extracted from $\mathrm{H}$. pylori 26695 wild-type. Lanes: 1 and 2, primers KatA $557 \mathrm{~F}$ and KatA 1249R, using RNA as the template (the $692 \mathrm{bp}$ product showing the presence of the katA transcript); 3 and 4, primers KatA $1001 \mathrm{~F}$ and KapA 103R, using RNA as template [absence of a product (predicted size of $770 \mathrm{bp}$ ) indicating that no single transcript exists for katA and kapA]; 5 and 6 , primers KapA $423 \mathrm{~F}$ and KapA 824R, using RNA as template (the $401 \mathrm{bp}$ product indicating that a transcript is present for $k a p A) ; 7$ and 8, primers KatA $557 \mathrm{~F}$ and KatA 1249R, using RNA as the template (reverse transcriptase was omitted from the reaction). The absence of any bands indicates that the RNA samples contain no genomic DNA; 9, primers KatA $557 \mathrm{~F}$ and KatA 1249R, using genomic DNA as a template (positive control); 10 , $1 \mathrm{~kb}$ marker. (b) Agarose gel of RT-PCR of RNA extracted from H. pylori 26695 wild-type and KatA-deficient mutant. Lanes: 1, $\lambda$ Hindlll digest; 2, $401 \mathrm{bp}$ product produced using primers KapA 423F and KapA 824R from RNA extract from wild-type $H$. pylori; 3, $401 \mathrm{bp}$ product produced using primers KapA 423F and KapA 824R from RNA extract from KatA-deficient strain of $H$. pylori, indicating that transcription of the KapA is occurring in the KatA isogenic mutant; 4 and 5, primers KapA 423F and KapA 824R used in an RT-PCR where the reverse transcriptase was omitted, indicating that RNA samples were free of DNA; 6 , primers KapA 423F and KapA 824R using genomic DNA extracted from wild-type $H$. pylori 26695 (this lane was a positive control).

lined in Table 1, confirming the orientation of aphA3 in each of these genes.

A PCR using the M13F and M13R sequencing primers (specific for plasmid DNA) was carried out to confirm that the DNA isolated from the isogenic mutants (a) $\begin{array}{lllllll}1 & 2 & 3 & 4 & 5 & 6 & 7\end{array}$

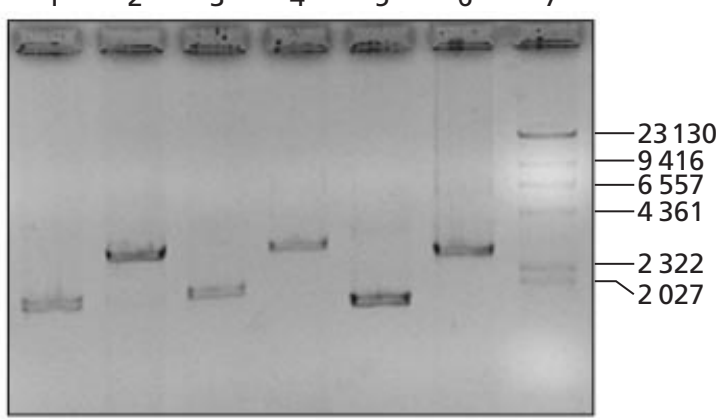

(b)

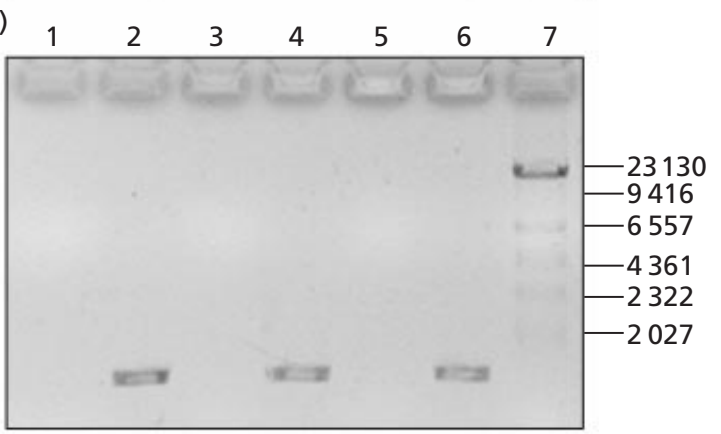

Fig. 3. Confirmation of katA, kapA (HP0874) and fur allelic exchange isogenic mutants. (a) A $0.8 \%(\mathrm{w} / \mathrm{v})$ agarose gel stained with ethidium bromide (lane, template, primers): 1, 26695 wild-type; HpKatA $F$ and HpKatA R; 2, 26695 katA::aphA3; HpKatA F and HpKatA R; 3, 26695 Wt; HpKapA F and HpKapA R; 4, 26695 kapA::aphA3; HpKapA F and HpKapA $\mathrm{R}$; 5, $26695 \mathrm{Wt}$; HpFur $\mathrm{F}$ and HpFur R; 6, 26695 fur::aphA3; HpFur F and HpFur R; 7, $\lambda$ HindIII, DNA marker. (b) A $0.8 \%$ (w/v) agarose gel stained with ethidium bromide (lane, template, primers): 1, 26695 wild-type; Kan I F and Kan I R; 2, 26695 katA::aphA3; Kan I F and Kan I R; 3, 26695 Wt; Kan I F and Kan I R; 4, 26695 kapA::aphA3; Kan I F and Kan I R; 5, 26695 Wt; Kan I F and Kan I R; 6, 26695 fur::aphA3; Kan I F and Kan I $\mathrm{R} ; 7, \lambda$ HindIII, DNA marker.

contained no DNA from the suicide vectors. No PCR product was obtained (data not shown).

\section{RT-PCR of kapA (HP0874) in katA isogenic mutant and wild-type}

In order to determine whether the isogenic mutant of kat $A$ was transcriptionally non-polar, RT-PCR was carried out on the RNA extracted from the wild-type $H$. pylori 26695 and the katA isogenic mutant (Fig. 2b). The primers used to determine whether kapA (HP0874) was expressed (KapA 423F; KapA 824R) produced a product $401 \mathrm{bp}$ in length when RNA extracted from the wildtype and the katA isogenic mutant were used as templates in the RT-PCR. The same reaction, with the omission of the reverse transcriptase, was also carried out. No product was produced, indicating the absence of DNA from the sample of RNA from the samples. These results indicate that the insertion of aphA3 into $k a t A$ is non-polar, as transcription of the downstream gene is unaffected. 


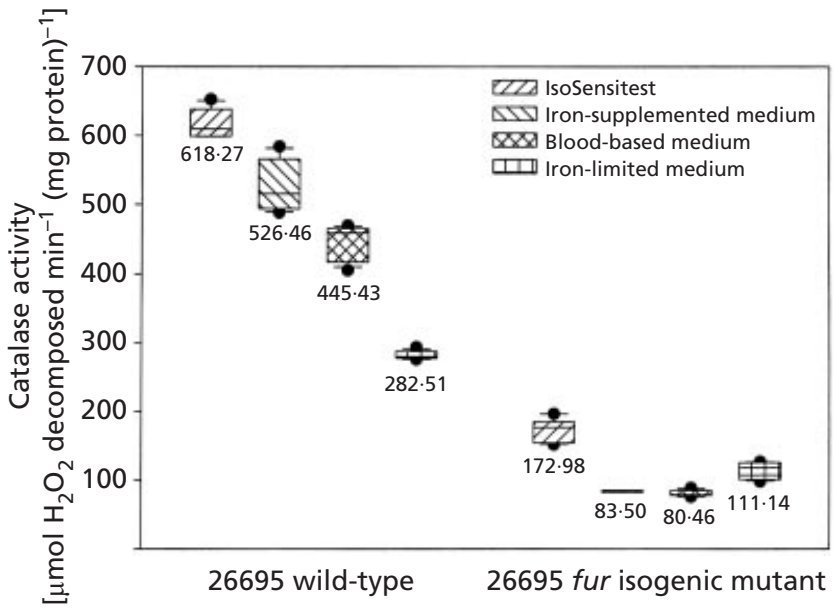

Fig. 4. Box plots of catalase activates $[\mu \mathrm{mol}$ hydrogen peroxide degraded $\min ^{-1}$ (mg protein) ${ }^{-1}$ ] of cell-free extracts of $H$. pylori 26695 wild-type and 26695 fur::aphA3 when grown on IsoSensitest, iron-supplemented, iron-depleted and blood-based media. Values under each box are the median value for the group (represented by the line in the middle of the box).

\section{Atomic absorbance spectroscopy of media}

Atomic absorbance spectroscopy was used to determine the amount of iron present in the medium. The medium that had been treated with Chelex (iron depleted) had a total $\mathrm{Fe}^{2+}$ content of $0.255 \mathrm{mg} \mathrm{l}^{-1}$. IsoSensitest supplemented with $5 \%$ horse serum (standard preparation) had a total $\mathrm{Fe}^{2+}$ content of $1.0 \mathrm{mg} \mathrm{l} l^{-1}$, approximately four times that of the iron-depleted medium. The total $\mathrm{Fe}^{2+}$ content of the iron-supplemented medium was $6.587 \mathrm{mg} \mathrm{l}^{-1}$, approximately 6.5 times greater than the IsoSensitest media and 26 times greater than the irondepleted medium. Atomic absorbance spectroscopy was not applied to CSA, due to the presence of erythrocytes.

\section{Catalase activities of cell-free extracts}

Catalase activities of cell-free extracts of wild-type and Fur-deficient mutants of $H$. pylori were measured to determine whether Fur and environmental iron (iron content of the medium) affected the catalase activity. Box plots of the catalase activities are presented in Fig. 4. There were statistically significant differences between the catalase activities of the wild-type strain and the Furdeficient mutant (Mann-Whitney $U$-test at a confidence level of $5 \%$ ), regardless of the medium used to culture the bacteria. The catalase activities of the Fur-deficient mutant were substantially lower than that of the wildtype cells.

The iron concentration of the media also affected the catalase activities of the cell (Fig. 4). Wild-type strain 26695 grown on the four different media shows that the differences observed between each the four groups are statistically significant (Kruskal-Wallis; $P \leqslant 0 \cdot 05$ ). Media with limited iron resulted in lower levels of catalase expression, whereas media with 'normal' levels of iron promoted catalase activity. Excessive levels of iron did
Table 2. Catalase activity of cell-free extracts of $H$. pylori 26695 wild-type and the $H$. pylori KapA-deficient and $H$. pylori KatA-deficient mutant

Activity was determined spectroscopically by the method of Beers \& Sizer (1952).The limit of sensitivity for the assay is 1 unit per milligram of protein. The results are means \pm SE.

\begin{tabular}{|lc|}
\hline & $\begin{array}{c}\text { Catalase activity }\left[\mu \mathrm{mol} \mathrm{H}_{2} \mathrm{O}_{2}\right. \\
\text { decomposed } \operatorname{~min}^{-1}(\mathbf{m g} \\
\left.\text { protein })^{-1}\right]\end{array}$ \\
\hline 26695 wild-type & $445 \cdot 43 \pm 25 \cdot 55$ \\
KapA-deficient mutant & $467 \cdot 30 \pm 10 \cdot 10$ \\
KatA-deficient mutant & $00 \cdot 00 \pm 00 \cdot 00$ \\
\hline
\end{tabular}

not promote catalase activity, with no significant difference in activity between cells grown on ironsupplemented medium compared with cells grown on a medium containing 'normal' levels of iron. Cell-free extracts prepared from cells grown on blood-based medium displayed lower catalase activities than cells grown on serum-based medium.

To test the interaction between HP0874 (KapA) and catalase, the catalase activities of the wild-type cells and the HP0874-deficient mutants were compared. Inactivation of HP0874 had no apparent effect on catalase activity, which is in accord with the results of Odenbreit et al. (1996) (Table 2).

\section{Response of $\boldsymbol{H}$. pylori to hydrogen peroxide}

To determine how important KatA, HP0874 (KapA) and Fur were to resistance of oxidative stress in $H$. pylori, time-course experiments, exposing H. pylori to hydrogen peroxide, were performed. As a negative control, the bacteria were cultured on the four different media and exposed to water for $1 \mathrm{~h}$, instead of hydrogen peroxide. There were no significant reductions in viability in any of the strains under the control conditions over the period of exposure (Fig. 5a).

When the strains of $H$. pylori grown on IsoSensitest medium were exposed to $\sim 100 \mathrm{mM}$ hydrogen peroxide, the KatA-deficient mutant experienced a rapid decline in viability (Fig. 5b). There was a decrease in viability of the HP0874 (KapA)-deficient mutant when exposed to $\sim 100 \mathrm{mM}$ hydrogen peroxide, and this was characterized by an initial lag period followed by a rapid decrease in viability (Fig. 5b). There was no apparent reduction in the viability of the Fur-deficient mutant and the control (26695 wild-type) (Fig. 5b).

H. pylori grown on iron-supplemented media and exposed to $\sim 100 \mathrm{mM}$ hydrogen peroxide (Fig. 5c) resulted in similar patterns to those of cells grown on IsoSensitest media without iron supplementation.

Growing the H. pylori strains on iron-limited media followed by exposure of the cells to $\sim 100 \mathrm{mM}$ hydrogen peroxide resulted in a rapid decrease in cellular viability 

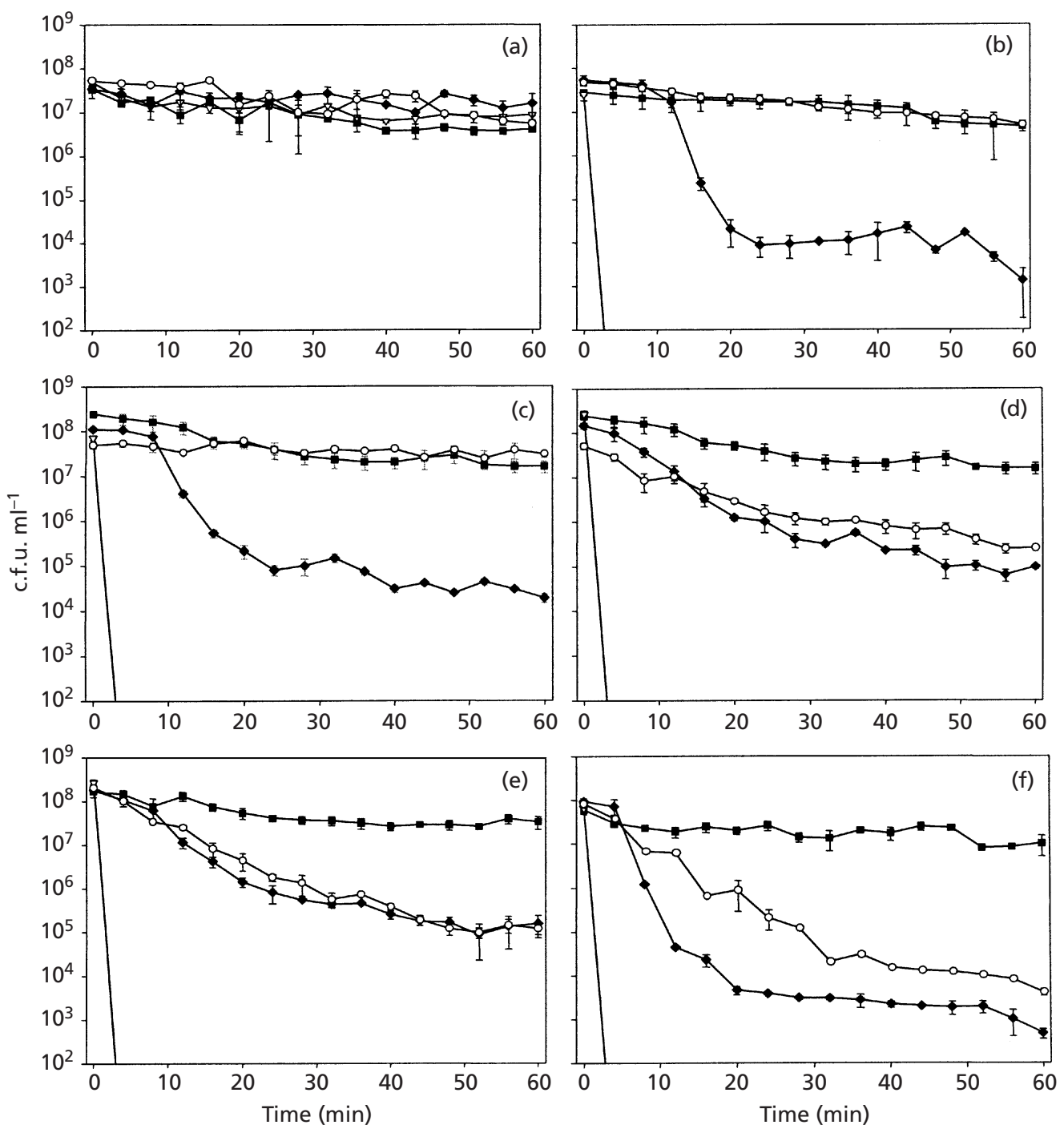

Fig. 5. Response of $H$. pylori 26695 wild-type ( $\square), 26695$ katA::aphA3( $\nabla), 26695$ kapA::aphA3 ( $\diamond)$ and 26695 fur::aphA3 $(\diamond)$ to: (a) water over time (negative control); (b) $98 \mathrm{mM}$ hydrogen peroxide when grown on IsoSensitest medium supplemented with $5 \%$ (v/v) horse serum; (c) $98 \mathrm{mM}$ hydrogen peroxide when grown on iron-supplemented medium; (d) $98 \mathrm{mM}$ hydrogen peroxide when grown on iron-limited medium; (e) $49 \mathrm{mM}$ hydrogen peroxide when grown on irondepleted medium; (f) $98 \mathrm{mM}$ hydrogen peroxide when grown on blood-based medium. The error bars represent the standard deviation of each group.

for the katA isogenic mutant (Fig. 5d). Both HP0874 (KapA)- and Fur-deficient mutants experienced significant reductions in viability compared to the wild-type cells. The initial lag observed with the HP0874 (KapA)deficient mutant, as noted above, was less apparent under these conditions. Rather, a decrease in viability during the first $20 \mathrm{~min}$ of exposure, which tapered off over the following $40 \mathrm{~min}$, was observed. The viability of the Fur-deficient mutant decreased similarly to the HP0874 (KapA)-deficient mutant.

Exposure of cells grown on blood-based media to $\sim 100 \mathrm{mM}$ hydrogen peroxide was fatal to the KatAdeficient mutant (Fig. 5f). The HP0874 (kapA) isogenic mutant exhibited an initial 4 min lag followed by a rapid loss of cellular viability ( $4 \operatorname{logs}$ or $99.99 \%$ ) over the initial $20 \mathrm{~min}$, the rate decreasing over the remaining 40 min. The Fur-deficient mutant also experienced a significant drop in viability, $4 \operatorname{logs}(99.99 \%)$, over the $60 \mathrm{~min}$ of exposure.

\section{DISCUSSION}

H. pylori has a potent set of antioxidant defences, including enzymes such as alkyl hydroperoxide reductase (Ahp), thioredoxin-linked thiol peroxidase (scavengase) (Alm et al., 1999; Cha et al., 1995; Stojiljkovic et al., 1994; Wan et al., 1997), superoxide dismutase (SodB) (Seyler et al., 2001; Spiegelhalder et al., 1993) and catalase (KatA) (Hazell et al., 1991). See Hazell et al. (2001) for a review. We have undertaken a study examining catalase and the potential interaction 
between katA and Fur, iron and a gene (HP0874) encoding a product that we have designated the KatAassociated protein (kapA). Not surprisingly, the katA isogenic mutant was shown to be hypersensitive to hydrogen peroxide. In contrast, wild-type cells were able to survive exposure to physiologically high concentrations of hydrogen peroxide $(\sim 100 \mathrm{mM})$. A catalasedeficient mutant of Campylobacter coli displayed a similar sensitivity when exposed to relatively low levels of hydrogen peroxide ( $1 \mathrm{mM})$ (Grant \& Park, 1995). That H. pylori wild-type was able to survive such high concentrations of hydrogen peroxide is indicative of the importance of catalase to the survival of the bacterium when exposed to ROS.

The catalase of $H$. pylori requires a haem prosthetic group. H. pylori has a number of iron-acquisition systems (Velayudhan et al., 2000), and isogenic mutants deficient in FeoB, a high-affinity ferrous transporter, while capable of growth in vitro, were unable to colonize the murine gastric mucosa (Velayudhan et al., 2000). In addition, iron can play an important role in the regulation of the genes encoding antioxidant defence enzymes via Fur, PerR and other iron-dependent mechanisms. Our data indicate that the iron concentration had a significant impact on catalase activity (Fig. 4). The significant drop in catalase activity of $H$. pylori wildtype cells grown on iron-limited media may relate to KatA being an iron-dependent enzyme. In an ironlimited environment, the cell's physiology might be focused towards iron acquisition with less catalase required or less iron available to form haem.

The Fur homologue of H. pylori was originally characterized by Bereswill and associates (Bereswill et al., 1998, 2000). Fur is an iron-dependent regulatory protein, regulating genes involved in iron uptake (Stojiljkovic et al., 1994). In certain bacteria, Fur also regulates, either positively or negatively, the acid-tolerance response, chemotaxis, motility, and the oxidative stress response (Hahn et al., 2000; Hassett et al., 1996; Horsburgh et al., 2001; Naik \& Hassan, 1992; Niederhoffer et al., 1990; Stojiljkovic et al., 1994). Fur upregulates catalase (KatB) from Pseudomonas aeruginosa and Staphylococcus aureus KatA (Horsburgh et al., 2001). Conversely, Fur downregulates the KatA in $P$. aeruginosa (Hassett et al., 1996) and C. jejuni (Van Vliet et al., 1999, 1998). These proteins are upregulated in the presence of iron in Fur mutants, indicating Fur-independent iron regulation of KatA in these bacteria, with the possible involvement of the iron-storage molecule bacterioferritin (Ma et al., 1999; Wai et al., 1996).

That Fur has different effects on the regulation of catalase in different bacteria is of interest. Part of the difference could relate to the global regulation of oxidative stress in different bacteria. For instance, in $E$. coli, fur is regulated by OxyR and SoxRS (Zheng et al., 1999). H. pylori lacks OxyR, SoxRS, RpoS, LexA and PerR homologues (Tomb et al., 1997), which may relate to the adaptation of the bacterium to life on the inflamed gastric mucosa. In such circumstances, regulation of KatA may be attuned more to differences in the flux of iron in an environment of near-constant oxidative stress. Delany et al. (2001a) demonstrated that Fur interacted with iron within the promoter of an iron-activated gene of $H$. pylori and suggested a model in which the iron status of the Fur protein differentially alters its affinity for operators in either iron-repressed or iron-activated genes.

A putative Fur-box has been identified upstream of katA (Manos et al., 1997; Odenbreit et al., 1996). Delany et al. (2001b) demonstrated, using Dnase I footprinting, two Fur-boxes in the intergenic region between katA and $f r p B$. The putative Fur-box immediately upstream of $k a t A$ was a low-affinity or type 2 Fur-box. Delaney et al. (2001b) were unable to identify any differences between the levels of specific transcript for kat $A$ in wild-type and Fur-deficient mutants. The cell-free extracts from the Fur-deficient mutant created in our study had a significantly lower catalase activity than the wild-type cells. Both wild-type and Fur-deficient mutants had high levels of catalase, differences that may not have been detected at the genetic level. Another explanation is the pleiotropic effect that disrupting Fur might have on the cell's physiology. Fur may impact on the synthesis of haem prosthetic groups required for the enzymic function. Massé \& Gottesman (2002) have recently shown in E. coli that iron, and ultimately Fur, regulates a small RNA molecule, RyhB, that in turn regulates a number of different genes involved in iron metabolism and other cellular enzymes such as succinate dehydrogenase and superoxide dismutase $(\operatorname{sod} B)$. The only region of the $H$. pylori $\mathrm{J} 99$ genome having any similarity to $r y b B$ was the $5^{\prime}$ end of the anthranilate synthase component I $(\operatorname{trp} E)$ (Altschul et al., 1997). The possibility remains, however, that unidentified systems, such as small RNA molecules involved in the post-transcriptional regulation of protein expression, may be influencing the catalase activity of the Fur-deficient mutants.

We previously demonstrated that as the relative erythrocyte concentration of a medium increased, the catalase activity of $H$. pylori decreased (Hazell et al., 1991). In this study, we have shown that Fur-deficient mutants of H. pylori appear to be more sensitive to hydrogen peroxide when grown on a blood medium (Fig. 5e), with a similar sensitivity to mutants grown on medium with depleted free iron (Fig. 5d). Thus, growth on whole blood mimics growth on iron-depleted media.

Downstream of kat $A$ is an ORF with no known function (Manos et al., 1997; Odenbreit et al., 1996). There were initially suggestions that this gene, HP0874 (kapA), was co-expressed with katA. Odenbreit et al. (1996) used transposon shuttle mutagenesis to disrupt HP0874 and the intergenic region between kat A and HP0874 (kapA). The catalase activities of these mutants were no different from the wild-type cells. These results failed to clarify the issue relating to possible co-translation. We have shown, using RT-PCR, that no co-transcription of katA and HP0874 occurs (Fig. 2). These results indicate, despite the absence of any recognizable RNA polymerase binding sites in the intergenic region, that kat $A$ and HP0874 (kapA) are expressed independently of each 
other. Further, disrupting the katA did not affect the expression of HP0874 (kapA) (Fig. 2b).

Exposing HP0874 (kapA) isogenic mutants to a high concentration of hydrogen peroxide resulted in cell death irrespective of the presence of active catalase. This was in contrast to the results of exposing the wild-type cells to hydrogen peroxide. These results indicate that HP0874 (KapA) plays a role in resistance to hydrogen peroxide. The rate at which the HP0874 (kapA) isogenic mutant lost viability was different to that of the katA isogenic mutant. Upon exposure to $\sim 100 \mathrm{mM}$ hydrogen peroxide, the HP0874 (KapA)-deficient mutant typically experienced a lag period followed by a rapid decrease in cell viability, and then the rate of loss decreased. It is critical to note that the HP0874 (kapA) mutants were catalase-positive (Table 2). This point is important as it was evident that catalase was rapidly depleting hydrogen peroxide in these experiments. Under these conditions, catalase could mask the importance of HP0874 (KapA). For this reason, the concentrations of hydrogen peroxide used in these experiments were high by comparison with physiological concentrations. That is, when catalasepositive HP0874 (KapA)-deficient mutants were exposed to hydrogen peroxide, the actual hydrogen peroxide concentration was rapidly and continuously decreasing. Therefore, the effective hydrogen peroxide concentration was much lower than $100 \mathrm{mM}$.

There are a number of possible functions for HP0874 (KapA), such as a chaperone, a transporter protein or a peroxide-sensing protein. Hydrogen peroxide can generate other peroxides (organic peroxides) (Farr et al., 1988). There are two known mechanisms for removing organic peroxides in $H$. pylori, alkyl hydroperoxide reductase (Alm et al., 1999; Hazell et al., 2001; Olczak et al., 2002; Tomb et al., 1997) and scavengase (Wan et al., 1997). Using 'identify function of unknown proteins', a BioNavigator macro (\#26487) (http:// www.bionavigator.com/), utilizing the programs HMMpfam, Garnier, Motifs (GCG), BlockSearcher and BlastP revealed that there were two small regions of HP0874 that have some similarity to the aldehyde ferredoxin oxidoreductase of the thermophilic archeon Pyrococcus furiosus (Chan et al., 1995) (E value 0.44) (data not shown). Aldehyde ferredoxin oxidoreductase is a tungsten-requiring enzyme responsible for catalysing the reversible oxidation of aldehydes to their corresponding carboxylic acid with the reduction of the ferredoxin. Ferredoxin $\mathrm{NADP}^{+}$reductases (FNR) have been identified as components of the oxidative stress response system of E. coli. FNR-deficient mutants display abnormal sensitivities to hydrogen peroxide (Krapp et al., 1997). Notwithstanding these features, HP0874 (KapA) appears unique. The HP0874 is conserved in all strains of $H$. pylori (Salama et al., 2000) with the only substantive homologue being a putative gene encoding a protein of unknown function in Pasteurella multocida (May et al., 2001) (http:// www.tigr.org).

Rain et al. (2001) noted a protein-protein interaction between KatA and HP0874 (KapA). The authors stated that recognition of protein-protein interactions 'allows prediction of protein function'. These data add to our observation that HP0874 has a role in the resistance to hydrogen peroxide, even if further functional analyses are required. Based on our data and the above finding, we have proposed the name KatA-associated protein, $k a p A$, for the gene and associated protein.

In conclusion, Fur knockouts and cells grown on a lowiron-containing medium showed a reduction in catalase activity and increased sensitivity to hydrogen peroxide. KapA-deficient mutants showed no reduction in catalase activity but did show an increase in sensitivity to hydrogen peroxide. Our data indicate that KatA is essential for the survival of $H$. pylori in the presence of hydrogen peroxide. Furthermore, KapA is an important component of the bacterium's resistance to oxidative damage, especially hydrogen peroxide. The evidence indicates that Fur and iron, either directly or indirectly, regulate catalase activity in $H$. pylori.

\section{ACKNOWLEDGEMENTS}

This work has been supported by a grant from the Australian Research Council.

\section{REFERENCES}

Alm, R., Ling, L., Moir, D. \& 20 other authors (1999). Genomic sequence comparison of two unrelated isolates of the human gastric pathogen Helicobacter pylori. Nature 397, 176-180.

Altschul, S. F., Madden, T. L., Schäffer, A. A., Zhang, J., Zhang, Z., Miller, W. \& Lipman, D. J. (1997). Gapped BLAST and PSIBLAST: a new generation of protein database search programs. Nucleic Acids Res 25, 3389-3402.

Beers, R. \& Sizer, I. (1952). A spectrophotometric method for measuring the breakdown of hydrogen peroxide by catalase. J Biol Chem 195, 133-140.

Bereswill, S., Lichte, F., Vey, T., Fassbinder, F. \& Kist, M. (1998). Cloning and characterization of the fur gene from Helicobacter pylori. FEMS Microbiol Lett 159, 193-200.

Bereswill, S., Greiner, S., Van Vliet, A. H. M., Waidner, B., Fassbinder, F., Schiltz, E., Kusters, J. G. \& Kist, M. (2000). Regulation of ferritin-mediated cytoplasmic iron storage by the ferric uptake regulator homolog (Fur) of Helicobacter pylori. J Bacteriol 182, 5948-5953.

Cadenas, E. (1989). Biochemistry of oxygen toxicity. Annu Rev Biochem 58, 79-110.

Cha, M. K., Kim, H. K. \& Kim, I. H. (1995). Thioredoxin-linked 'thiol peroxidase' from the periplasmic space of Escherichia coli. J Biol Chem 270, 28635-28641.

Chan, M. K., Mukund, S., Kletzin, A., Adams, M. W. W. \& Rees, D. C. (1995). Structure of a hyperthermophilic tungstopterin enzyme, aldehyde ferredoxin oxidoreductase. Science 267, 1463-1469.

Copass, M., Grandi, G. \& Rappuoli, R. (1997). Introduction of unmarked mutations in the Helicobacter pylori vacA gene with a sucrose sensitivity marker. Infect Immun 65, 1949-1952.

Crabtree, J. (1996). Immune and inflammatory responses to Helicobacter pylori infection. Scand J Gastroenterol 31, 3-10. 
Delany, I., Spohn, G., Rappuoli, R. \& Scarlato, V. (2001a). The Fur repressor controls transcription of iron-activated and -repressed genes in Helicobacter pylori. Mol Microbiol 42, 1297-1309.

Delany, I., Pacheco, A. B. F., Spohn, G., Rappuoli, R. \& Scarlato, V. (2001b). Iron-dependent transcription of the $f r p B$ gene of Helicobacter pylori is controlled by the Fur repressor protein. J Bacteriol 183, 4932-4937.

Dixon, M. (1994). Pathophysiology of Helicobacter pylori infection. Scand J Gastroenterol Suppl 29, 7-10.

Eaton, K., Brooks, C., Morgan, D. \& Krakowka, S. (1991). Essential role of urease in pathogenesis of gastritis induced by Helicobacter pylori in gnotobiotic pigs. Infect Immun 59, 2470-2475.

Ernst, P. (1999). Review article: the role of inflammation in the pathogenesis of gastric cancer. Aliment Pharmacol Ther 13, 13-18.

Farr, S., Touati, D. \& Kogoma, T. (1988). Effects of oxygen stress on membrane functions in Escherichia coli: role of HPI catalase. J Bacteriol 170, 1837-1842.

Feldman, R. A., Eccersley, A. J. P. \& Hardie, J. M. (1997). Transmission of Helicobacter pylori. Curr Opin Gastroenterol 13S1, 8-12.

Graham, D. (1989). Campylobacter pylori and peptic ulcer disease. Gastroenterology 96, 615-625.

Grant, K. A. \& Park, S. F. (1995). Molecular characterisation of katA from Campylobacter jejuni and generation of a catalasedeficient mutant of Campylobacter coli by interspecific allelic exchange. Microbiology 141, 1369-1376.

Hahn, J., Oh, S. \& Roe, J. (2000). Regulation of furA and catC operon, encoding a ferric uptake regulator homologue and catalase-peroxidase, respectively, in Stretomyces coelicolor A3(2). J Bacteriol 182, 3767-3774.

Hanahan, D. (1983). Studies on transformation of Escherichia coli with plasmids. J Mol Biol 166, 557-580.

Harris, A. G. \& Hazell, S. L. (2000). Helicobacter pylori: from discovery to genome. In Recent Advances in Microbiology, pp. 213-243. Edited by V. Ashe. Hawkesburn, Australia: Control Publications.

Hassett, D. J., Sokol, P. A., Howell, M. L., Ma, J. F., Schweizer, H. T., Ochsner, U. A. \& Vasil, M. L. (1996). Ferric uptake regulator (fur) mutants of Pseudomonas aeruginosa demonstrate defective siderophore-mediated iron uptake, altered aerobic growth, and decreased superoxide dismutase and catalase activities. J Bacteriol 178, 3996-4003.

Hazell, S. L., Borody, T., Gal, A. \& Lee, A. (1987). Campylobacter pyloridis gastritis. I. Detection of urease as a marker of bacterial colonization and gastritis. Am J Gastroenterol 82, 292-296.

Hazell, S. L., Markesich, D. C., Evans, D. J., Evans, D. G. \& Graham, D. Y. (1989). Influence of media supplements on growth and survival of Campylobacter pylori. Eur J Clin Microbiol Infect Dis 8, 597-602.

Hazell, S., Evans, D., Jr \& Graham, D. (1991). Helicobacter pylori catalase. J Gen Microbiol 137, 57-61.

Hazell, S. L., Harris, A. G. \& Trend, M. A. (2001). In Evasion and Avoidance of the Toxic Effects of Oxygen, pp. 167-175. Edited by H. L. T. Mobley, G. L. Mendz \& S. L. Hazell. Washington, DC: American Society for Microbiology.

Herbig, A. F. \& Helmann, J. D. (2001). Roles of metal ions and hydrogen peroxide in modulating the interaction of the Bacillus subtilis PerR peroxide regulon repressor with operator DNA. Mol Microbiol 41, 849-859.
Horsburgh, M. J., Ingham, E. \& Foster, S. J. (2001). In Staphylococcus aureus, Fur is an interactive regulator with PerR, contributes to virulence, and is necessary for oxidative stress resistance through positive regulation of catalase and iron homeostasis. J Bacteriol 183, 468-475.

Krapp, A. R., Tognetti, V. B., Carrillo, N. \& Acevedo, A. (1997). The role of ferredoxin-NADP ${ }^{+}$reductase in the concerted cell defense against oxidative damage - studies using Escherichia coli mutants and cloned plant genes. Eur J Biochem 249, 556-563.

Ma, J. F., Ochsner, U. A., Klotz, M. G. \& 7 other authors (1999). Bacterioferretin A modulates catalase A (KatA) activity and resistance to hydrogen peroxide in Pseudomonas aeruginosa. J Bacteriol 181, 3730-3742.

Manos, J. (1998). Molecular characterisation of the Helicobacter pylori catalase. PhD thesis, School of Microbiology and Immunology, University of New South Wales, Sydney.

Manos, J., Kolesnikow, T. \& Hazell, S. L. (1997). An investigation of the molecular basis of the spontaneous occurrence of a catalase negative phenotype in Helicobacter pylori. Helicobacter 3, 28-38.

Massé, E. \& Gottesman, S. (2002). A small RNA regulates the expression of genes involved in iron metabolism in Escherichia coli. Proc Natl Acad Sci U S A 99, 4620-4625.

May, B. J., Zhang, Q., Li, L. L., Paustian, M. L., Whittam, T. S. \& Kapur, V. (2001). Complete genomic sequence of Pasteurella multocida, Pm70. Proc Natl Acad Sci US A 98, 3460-3465.

Mendz, G. L., Holmes, E. M. \& Ferrero, R. L. (1998). In situ characterization of Helicobacter pylori arginase. Biochim Biophys Acta 1388, 465-477.

Mooney, C., Keenan, J., Munster, D., Wilson, I., Allardyce, R., Bagshaw, P., Chapman, B. \& Chadwick, V. (1991). Neutrophil activation by Helicobacter pylori. Gut 32, 853-857.

Naik, S. N. \& Hassan, H. M. (1992). Use of site-directed mutagenesis to identify an upstream regulatory sequence of $s o d A$ gene in Escherichia coli K12. Proc Natl Acad Sci U S A 87, 2618-2622.

Niederhoffer, E. C., Naranjo, C. M., Bradley, K. L. \& Fee, J. A. (1990). Control of Escherichia coli superoxide dismutase $(\operatorname{sod} A$ and $\operatorname{sodB}$ ) genes by the ferric uptake regulation (fur) locus. J Bacteriol 172, 1930-1938.

Nunoshiba, T., Obata, F., Boss, A. C., Oikawa, S., Mori, T., Kawanishi, S. \& Yamamoto, K. (1999). Role of iron and superoxide for generation of hydroxyl radical, oxidative DNA lesions, and mutagenesis in Escherichia coli. J Biol Chem 274, 34832-34837.

Odenbreit, S., Wieland, B. \& Haas, R. (1996). Cloning and genetic characterisation of Helicobacter pylori catalase and construction of a catalase deficient mutant. J Bacteriol 178, 6960-6967.

Olczak, A. A., Olson, J. W. \& Maier, R. J. (2002). Oxidative stress resistance mutants of Helicobacter pylori. J Bacteriol 184, 3186-3193.

Parsonnet, J., Friedman, G., Vandersteen, D., Chang, Y., Vogelman, J., Orenteich, N. \& Sibley, R. (1991). Helicobacter pylori infection and the risk of gastric carcinoma. N Engl J Med 325, 1127-1131.

Rain, J., Selig, L., De Reuse, H. \& 10 other authors (2001). The protein-protein interaction map of Helicobacter pylori. Nature 409, 211-215.

Ramarao, N., Gray-Owen, S. D. \& Meyer, T. F. (2000). Helicobacter pylori induces but survives the extracellular release of oxygen radicals from professional phagocytes using its catalase activity. Mol Microbiol 36, 103-113.

Salama, N. R., Guillemin, K., McDaniel, T. K., Sherlock, G., Tompkins, L. \& Falkow, S. (2000). A whole-genome microarray 
reveals genetic diversity among Helicobacter pylori strains. Proc Natl Acad Sci U S A 97, 14668-14673.

Sambrook, J., Fritsch, E. F. \& Maniatis, T. (1989). Molecular Cloning: a Laboratory Manual, 2nd edn. Cold Spring Harbor, NY: Cold Spring Laboratory.

Seyler, R. W., Olson, J. W. \& Maier, R. J. (2001). Superoxidedismutase deficient mutants of Helicobacter pylori are hypersensitive to oxidative stress and defective in host colonisation. Infect Immun 69, 4034-4040.

Skirrow, M. (1977). Campylobacter enteritis: a 'new' disease. Br Med J 2, 9-11.

Spiegelhalder, C., Gerstenecker, B., Kersten, A., Schiltz, E. \& Kist, M. (1993). Purification of Helicobacter pylori superoxide dismutase and cloning and sequencing of the gene. Infect Immun 61, 5315-5325.

Stojiljkovic, I., Baumler, A. \& Hantke, K. (1994). Fur regulation in Gram negative bacteria: identification and characterisation of new iron-regulated Escherichia coli genes by a Fur titration assay. J Mol Biol 236, 531-545.

Tillet, D., Burns, B. \& Neilan, B. (2000). Optimised rapid amplification of cDNA ends (RACE) for mapping bacterial mRNA transcripts. Biotechniques 28, 448-456.

Tomb, J., White, O., Kerlavage, A. \& 39 other authors (1997). The complete genome sequence of the gastric pathogen Helicobacter pylori. Nature 388, 539-547.

Uemura, N., Okamoto, S., Yamamoto, S., Matsumara, N., Yamaguchi, S., Yamakido, M., Taniyama, K., Sasaki, N. \& Schlemper, R. J. (2001). Helicobacter pylori infection and the development of gastric cancer. N Engl J Med 345, 784-789.
Van Vliet, A. H. M., Wooldridge, K. G. \& Ketley, J. M. (1998). Ironresponsive gene regulation in a Campylobacter jejuni fur mutant. J Bacteriol 180, 5291-5298.

Van Vliet, A. H. M., Baillon, M. A., Penn, C. W. \& Ketley, J. M. (1999). Campylobacter jejuni contains two Fur homologs: characterization of iron-responsive regulation of peroxide stress defense genes by the PerR repressor. J Bacteriol 181, 6371-6376.

Velayudhan, J., Hughes, N. J., McColm, A. A., Bagshaw, J., Clayton, C. L., Andrews, S. C. \& Kelly, D. J. (2000). Iron acquisition and virulence in Helicobacter pylori: a major role for FeoB, a high affinity ferrous iron transporter. Mol Microbiol 37, 274-286.

Wai, S. N., Nakayama, K., Umene, K., Moriya, T. \& Amako, K. (1996). Construction of a ferritin-deficient mutant of Campylobacter jejuni: contribution of ferritin to iron storage and oxidative stress. Mol Microbiol 20, 1127-1134.

Wan, X. Y., Zhou, Y., Yan, Z. Y., Wang, H. L., Hou, Y. D. \& Jin, D. Y. (1997). Scavengase $\mathrm{p} 20$ : a novel family of bacterial antioxidant enzymes. FEBS Lett 407, 32-36.

Westblom, T., Phadnis, S., Langenberg, W., Yoneda, K., Madan, E. \& Midkiff, B. (1992). Catalase negative mutants of Helicobacter pylori. Eur J Clin Microbiol Infect Dis 11, 522-526.

Wotherspoon, A., Ortitz-Hidalgo, C., Falzon, M. \& Isaacson, P. (1991). Helicobacter pylori associated gastritis and B-cell gastric lymphoma. Lancet 338, 1175-1176.

Zheng, M., Doan, B., Schneider, T. D. \& Storz, G. (1999). OxyR and SoxRS regulation of fur. J Bacteriol 181, 4639-4643.

Received 11 July 2002; revised 27 August 2002; accepted 4 September 2002. 